\title{
Laboratory Evaluation of a Method Proposed by Gnam for Measuring the Temperature of Rotating Parts
}

\author{
By Andrew I. Dahl and Paul D. Freeze
}

\begin{abstract}
A thermocouple application suggested by Gnam for measuring the temperature of rotating parts without slip rings or telemetering has been investigated. A rotating circuit, consisting of a thermocouple in series with the rotor coils of a converter, and a stationary circuit, consisting of the stator coils of the converter and a transformer, are linked magnetically. One thermocouple junction is fixed to the rotating part whose temperature is to be measured, and the other protrudes from a hollow shaft into a furnace. The temperature of the rotating part is stationary circuit, as determined by an oscilloscope, used as a null indicator. Full-scale application of this system seems practicable.
\end{abstract}

\section{Introduction}

As one phase of a project at the National Bureau of Standards sponsored by the Bureau of Ships, Department of the Navy, for studying means of measuring temperatures of interest in operating gas turbines, a method proposed by E. Gnam ${ }^{1}$ for determining the temperature of rotating parts, such as turbine blades, has been evaluated. The proposed method seemed attractive, as it involved neither slip rings nor telemetering.

The small-scale apparatus used in these tests differs considerably from that of Gnam and was not intended as a prototype for installations on actual turbines. However, it is believed that the present results show that full-scale application would be practicable and provide the basic information required for designing a service unit.

\section{Laboratory Test System}

The basic elements of the measuring system can be explained by reference to a schematic diagram, figure 1. Two separate circuits, linked magnetically, are involved. All parts of one circuit rotate, while all parts of the other are stationary.

The rotating circuit consists of a nickel-chromel thermocouple in series with the moving coils of a specially designed converter. One junction is located on a rotating part whose temperature is to

${ }^{1}$ A new apparatus for measuring the temperature at machine parts rotating at high speeds, E. Gnam, NACA Technical Memorandum No. 1080, April 1945. Original in Motortechnische Z. 5. No. 10, 289 (Oct. 1943). be determined, and the other is coaxial with and protruding from the hollow shaft of the converter. The protruding junction is surrounded by a furnace whose temperature can be controlled and measured by conventional means. When its temperature is equal to that of the second junction, the only emfs in the rotating circuit are strays that can be kept very small.

The stationary circuit consists of the fixed coils of the converter connected to an impedancematching transformer and an oscilloscope for indicating output.

The details of the converter used in the laboratory tests are shown in figure 2. In designing this converter, representatives of the Electricity and Optics Division of the National Bureau of Standards were concerned initially as to whether adequate sensitivity could be achieved and particularly as to the proper width of the air gaps in the magnetic circuit. It seemed desirable, therefore, to build the laboratory unit with the pole faces normal to the axis of the shaft and to provide for adjusting the gaps by changing the position of the rotor on the shaft.

It also seemed desirable to connect the two coils of each circuit by magnetic circuits of high permeability. Hence the two poles (each $1 / 4$ in. diameter by $5 / 16$ in. long) of each unit were machined on the end of an appropriate cylinder of Mu metal. A cylindrical shield of $\mathrm{Mu}$ metal was provided to shield the coils from external magnetic fields. All Mu-metal parts were finally 


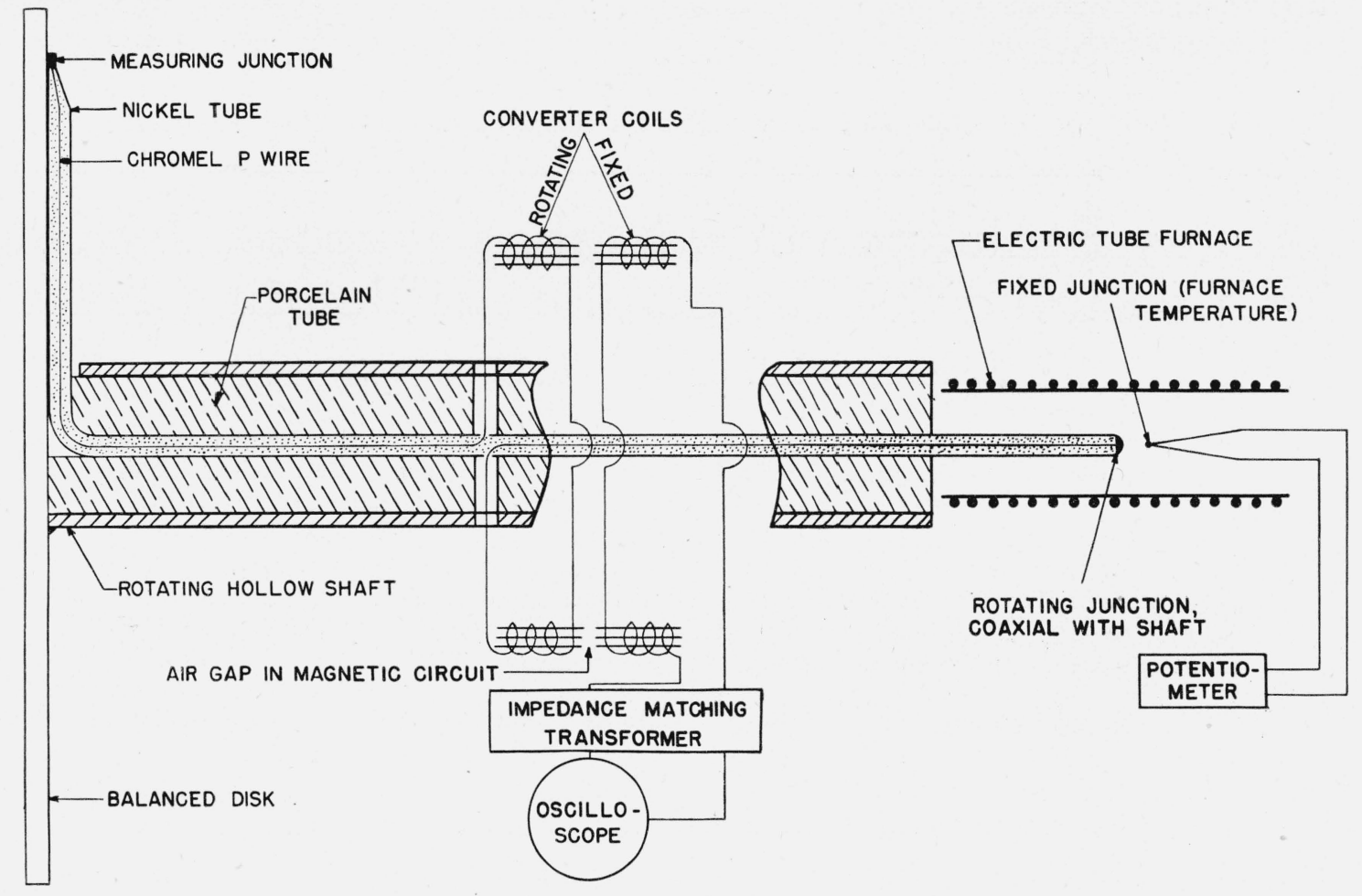

Figure 1. Schematic diagram of the laboratory apparatus.

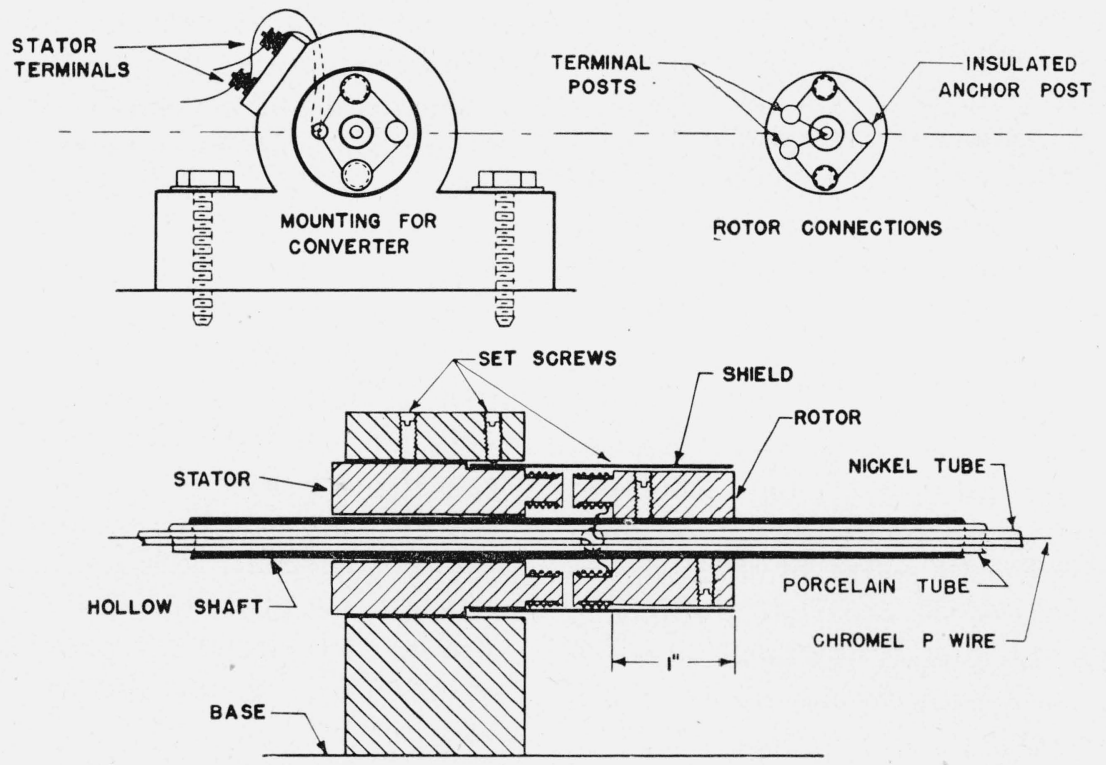

Figure 2. Details of converter used in tests. 


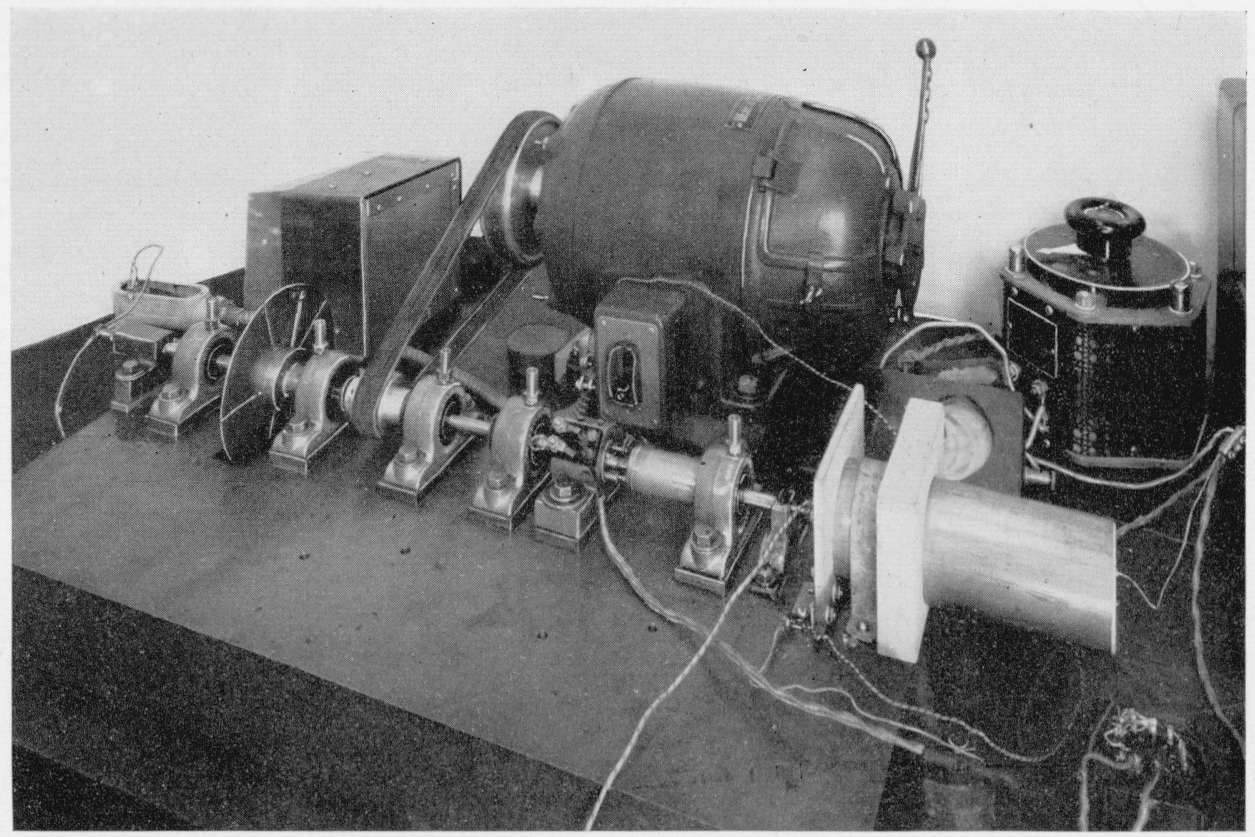

Figure 3. Apparatus used in tests.

annealed in hydrogen for 4 hours at about $2,000^{\circ} \mathrm{F}$ to improve the permeability, which is normally decreased by cold working.

Each of the four coils was wound with 85 turns of No. 26 insulated copper wire. The two rotor coils were connected in series, as were the two stator coils. The rotor unit was attached to the shaft by set screws. The stator unit and the cylindrical shield were mounted in a brass housing secured to the base.

Figure 3 shows the apparatus used in these tests. The shaft is a stainless steel tube $\left(\left(\frac{3}{8}-\mathrm{in}\right.\right.$. outside diameter and 0.06 -in. wall) provided with five pillow-block ball bearings secured to a plane cast iron base. These bearings can be identified by the vertical oilers. The longitudinal position of the shaft is fixed by a ball thrust bearing at the extreme left.

The disk used to simulate a turbine wheel is $6 \mathrm{in}$. in diameter and $1 / 16$ in. thick, with five equally spaced radial slots to reduce warping when flame is applied at the periphery. One junction of the thermocouple can be seen in an almost vertical position on the near side of the disk.

To the rear of the disk stands a metal box, partly open on the left, which was set over the disk during the tests. An oxyacetylene flame was directed through the opening in this box to heat the periphery of the disk.
The shaft is driven through a light fabric belt by a variable-speed alternating-current motor. Final adjustment of the shaft speed to any chosen value, as indicated by a Strobotac, was made by applying a rubber brake to the left face of the motor pulley.

The converter is shown in its mount between the last two bearings on the right. Near the right-hand bearing and surrounding the shaft is the cylindrical shield of Mu metal, which, during operation, is moved to the left to surround the coils of the converter that are barely visible because of their small size.

Mounted at the right of the base plate and concentric with the shaft is the tube furnace, which surrounds the second junction of the rotating thermocouple. The temperature of this furnace is controlled by adjusting a Variac and indicated by a chromel-alumel thermocouple. The necessary instruments, being standard items, are not shown in the photograph.

One of the problems in a system of this type is to design the rotating thermocouple so that the emf generated by its rotation in external magnetic fields (such as that of the earth) are negligibly small. This can be accomplished by making the two thermoelements coaxial, which in turn can be achieved by using one in tubular form around the other in the form of an insulated wire. Since 
the thermoelectric properties of the combination nickel-chromel $P$ are favorable, and since nickel tubing can be procured and worked with ease, this construction was used for the rotating couple. A porcelain tube served to center the thermocouple and to insulate it from the shaft. The nickel tube was insulated from the rotating disk by a sleeve of fiber glass.

The resistance of the rotating circuit at room temperature is about 2.5 ohms, divided about equally between the rotor coils and the thermocouple. All electrical connections in the stationary indicating circuit are made with shielded wire.

\section{Calibration and Performance Tests}

Although the measurements in actual service would be made by using the oscilloscope as a null instrument to indicate equality of temperature of the two rotating junctions, the potentialities of the method can be studied best when the temperatures of these two junctions differ by a known amount. Hence most of the present measurements were of deflections of the oscilloscope beam. To make such observations comparable it is necessary to keep the amplification factor constant, and this was done, as nearly as was practicable, throughout all of the observations reported here.

Several series of tests were made, only one operating factor being varied in each.

\section{Deflection Versus Temperature Difference}

At a constant shaft speed of 5,000 rpm and gap width of 0.003 in., and with the rotating disk at the temperature of the room, the temperature of the junction rotating within the furnace was raised by small increments, with the results shown in figure 4 . The average deflection under these conditions was 0.077 in. $/{ }^{\circ} \mathrm{F}$.

The observations shown in figure 4 were made over a period of several weeks, during which the gap width was changed many times. Inability to readjust the gap to exactly 0.003 in. is responsible for part of the spread. Some of it was probably caused by imperfect magnetic shielding and some by small changes in amplification.

It will be noted that the furnace temperature had to be made $7 \mathrm{deg} \mathrm{F}$ less than the disk temperature in order to obtain a minimum deflection. It is believed that this effect is produced by residual magnetism in the Mu metal, which produced a

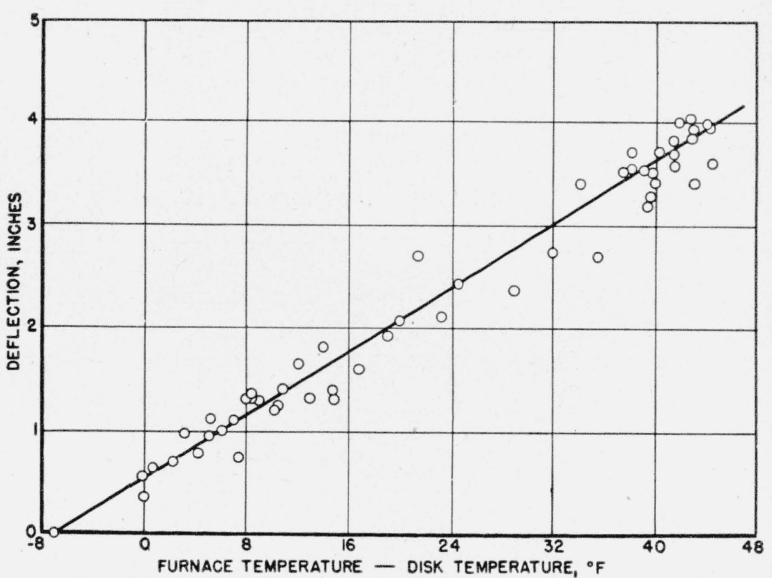

Figure 4. Sensitionty at 5,000 rpm with an air gap o. $0.003 \mathrm{in}$.

small voltage in the stator of the converter when no current flowed through the rotor coils.

The differences in temperature between furnace and disk were measured in this case directly by a chromel-alumel thermocouple having one junction in the furnace and the other at the disk. Since the junction could not be held against the disk while the latter was rotating, measurements of $\Delta T$ wer made before and after each operation, and the average of these two values was plotted in the figure.

In addition to the effect of residual mag netism, the effects of external magnetic field and of unequal air gaps were not completely eliminated, as evidenced by the fact that the oscilloscope trace could never be made a horizontal straight line. This trace, however, showed a sudden and marked change when the net voltage in the rotating circuit was zero. Because of this sudden change in the trace, there is no difficulty in determining the null condition.

\section{Deflection Versus Shaft Speed}

Again the gap was maintained at 0.003 in., and three trials were made over the range 1,000 to $10,000 \mathrm{rpm}$. In one the rotating circuit was open, so that the effect of residual magnetism in the magnetic circuit was determined. These results are shown in the lower curve of figure 5 . In the others, constant differences of 10 and 20 $\operatorname{deg} \mathrm{F}$ were maintained between the furnace and the disk, with the results shown in the upper curves of figure 5. All of the results show that 


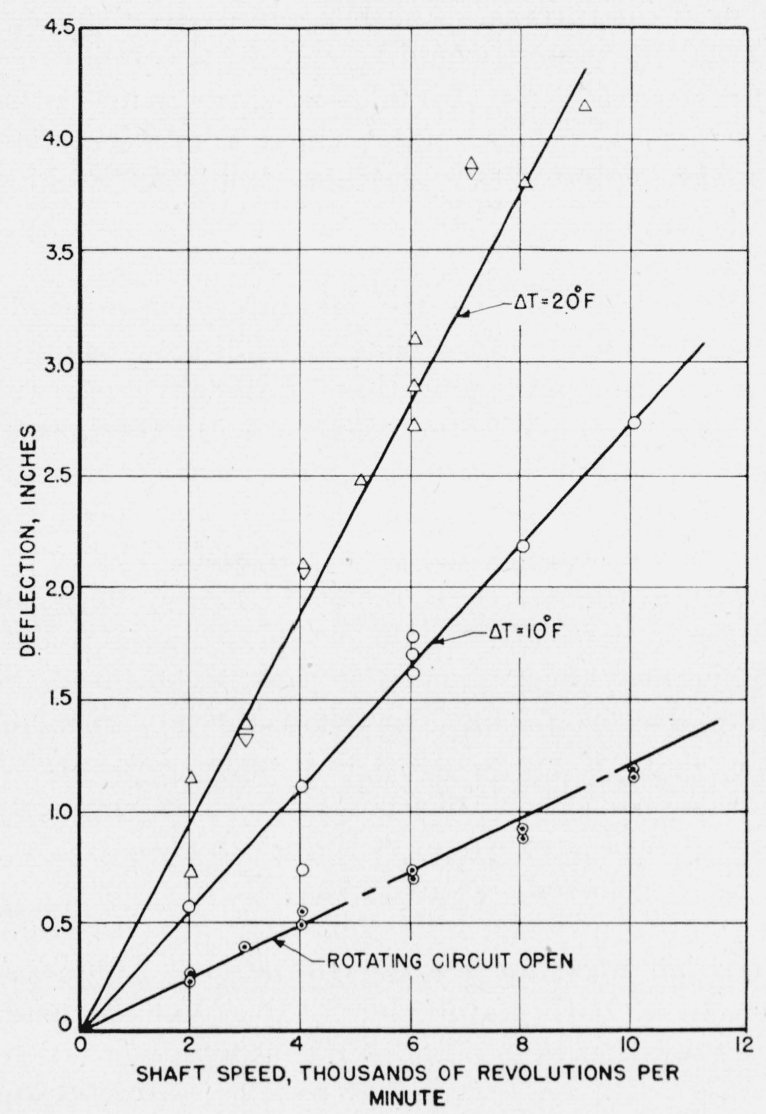

Figure 5. Sensitivity as a function of shaft speed with an air gap of $0.003 \mathrm{in}$.

the observed deflection is directly proportional to the shaft speed.

Typical oscilloscope traces at $6,000 \mathrm{rpm}$ and with temperature differences of 10 and $20 \mathrm{deg}$ $\mathrm{F}$ are shown in figure 6 . The squares on the oscilloscope scale are $0.1 \mathrm{in}$. on a side.

\section{Deflection Versus Gap Width}

The magnetic linkage between the stator and rotor of the converter and hence also the voltage induced in the rotor are a function of the width of the air gaps. With shaft speed constant at $6,000 \mathrm{rpm}$ and with a constant temperature difference of 10 deg $\mathrm{F}$ between the furnace and the disk, a series of tests was made at various gap widths from 0.002 to 0.021 in., with the results shown in figure 7 . As was anticipated, the sensitivity decreases rapidly as the air gap is increased from a small value, and this decrease becomes more gradual as the gap is widened.
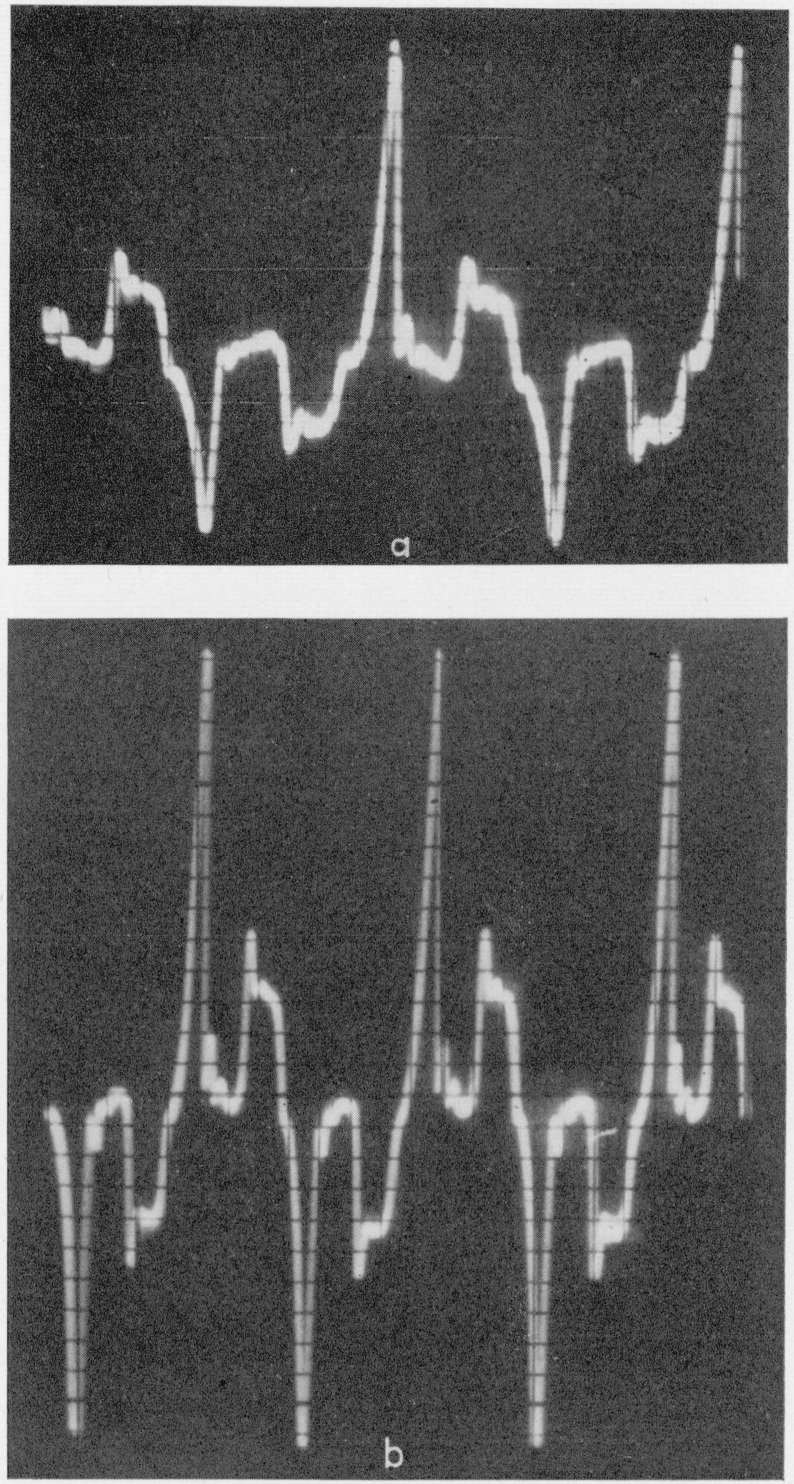

Figure 6. Typical oscilloscope traces.

a, $\triangle T=10^{\circ} \mathrm{F} ; \mathrm{rpm}=6,000 ; \mathrm{b}, \triangle T=20^{\circ} \mathrm{F} ; \mathrm{rpm}=6,000$.

If it is necessary, from a mechanical standpoint, to design the operating unit with a gap width that is relatively great, the loss in sensitivity therefrom can be overcome by increasing the number of poles on the converter. From the data of figure 7 it can be seen that increasing the gap width from 0.003 to 0.01 in. reduced the sensitivity by 50 percent. However, some sensitivity can be regained by the use of a four-pole converter instead of the present two-pole converter. 


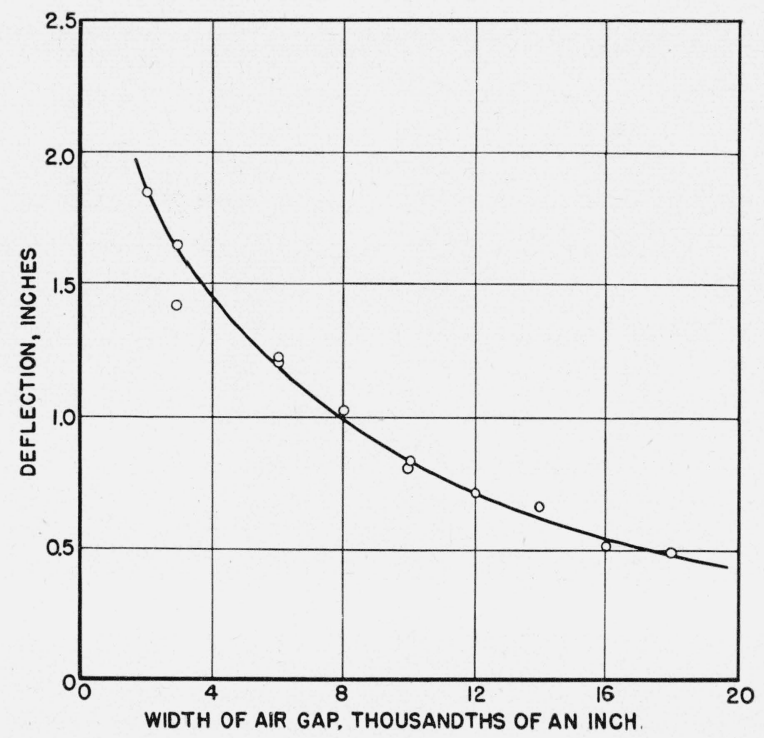

Figure 7. Sensitivity as a function of the width of the air $\mathrm{rpm}=6,000 ; \triangle T=10^{\circ} \mathrm{F}$.

\section{Tests at Elevated Temperature}

In all of the tests that have been discussed, the disk was at the temperature of the room. The results, however, are applicable at higher temperatures, since the changes in resistance and in thermoelectric properties of the nickel-chromel couple with temperature are of secondary importance.

Performance tests were also conducted by heating the periphery of the disk with an oxy-acetylene flame. A metal housing around the disk during these tests served to concentrate the flame on the periphery of the disk and to shield other parts of the apparatus against overheating.

At speeds up to $10,000 \mathrm{rpm}$ and disk temperatures to $1,500^{\circ} \mathrm{F}$, it was a simple matter to detect by eye a marked change in the pattern on the oscilloscope screen when the net emf in the rotating circuit became zero. Thus there is every reason to believe that the method can be applied for measuring the temperatures of rotating parts.

\section{Discussion of Possible Full-Scale Application}

It is obvious that a system such as has been described would be difficult to install on an existing full-scale turbine. Actually it seems probable that provision for installing such a system would have to be made during the design and construc- tion of the turbine. Another serious disadvantage is that the system would become quite complicated if it were to be used for measuring the temperature at more than one point, since a multiple unit would require either switching from one working junction to another or a converter for each working junction.

Some features of the laboratory unit would require considerable change in full-scale application. Principal among these is the air gap in the magnetic circuit of the converter. In the laboratory apparatus longitudinal movement of the shaft was prevented by thrust bearings, and there was no thermal expansion to contend with. Hence the width of the gap could be fixed by positioning the rotor on the shaft. In the actual turbine the shaft may move longitudinally, so that the stator of the converter would have to follow the movement of the shaft, if gap width is to remain constant. A mechanism capable of accomplishing such positioning of the stator would be quite complex.

It is believed, however, that the converter can be redesigned along the following lines to eliminate all need for moving the stator. The pole pieces of both stator and rotor should be made radial rather than parallel to the shaft, so that the rotor could be surrounded by the stator, in the manner indicated in figure 8 . The air gap would thus be an annulus, and it seems reasonable that the gap between stator and rotor poles could be of the order of $0.01 \mathrm{in}$.

If the minimum practicable air gap is decided upon and the normal speed of the shaft is known, the circuit and pick-up unit required to provide the desired sensitivity can then be designed. It

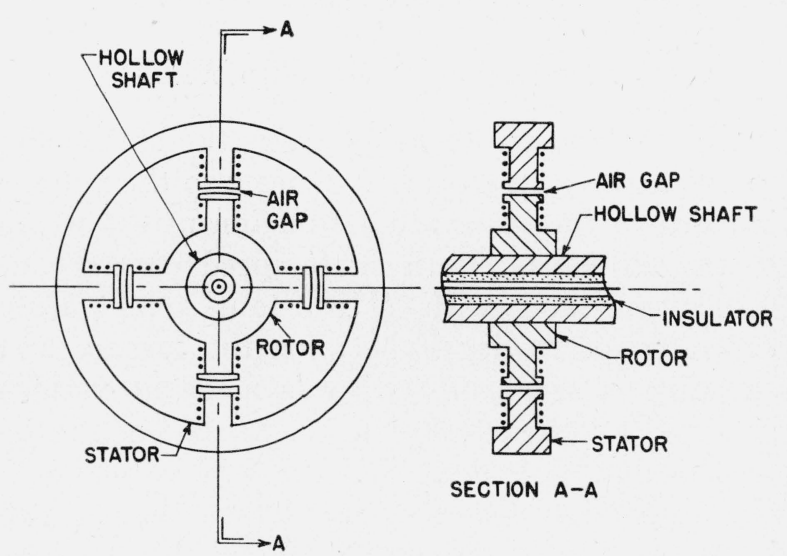

Figure 8. Schematic diagram of a converter for full-scale applications. 
should be noted that if a multipolar unit is to be used, the matching of impedances within the circuit must be considered. It is believed that a unit having a sensitivity of $10^{\circ} \mathrm{F}$ is feasible with an air gap of 0.01 in. and a shaft speed of 6,000 rpm.

It will be noted that the above estimates pertain to the accuracy with which the temperature indicated by the measuring junction is observed and not to the actual temperature of the turbine blade. If the measuring junction is completely buried in the blade and in good thermal contact with it, these two temperatures may be nearly the same.

As to the rotating thermocouple itself, the use of an insulated chromel $P$ wire within a nickel tube would seem to be well suited for full-scale application.

The rotating parts of the laboratory apparatus were not balanced dynamically. Since the fullscale application would be so much larger than the laboratory version, it is possible that the problem of achieving proper balance would be more serious. With radial rotor coils located at a considerable distance from the axis of the shaft, it may be necessary to confine the windings mechanically.

Since the magnetic shielding of the laboratory apparatus was not entirely satisfactory, even more effective shielding should be applied to the fullscale converter.

\section{Conclusion}

The present tests on a laboratory scale indicate that the method examined has considerable promise for measuring the temperature of rotating parts. Principal limitations are that the system would be difficult to install on an existing turbine and that it is suited for measuring the temperature at one point only. On the basis of present experience, several suggestions are made as to the design of a full-scale unit.

The assistance of F. K. Harris and A. W. Spinks of the Electricity and Optics Division in the design of the converter and in improving the electrical system, and of A. F. Baillie in the mechanical design and construction of the entire test system, is gratefully acknowledged.

Washington, July 27, 1948. 